
\title{
ROLIEW ARTICLE WASTE: ITS IMPLICATION FOR HEALTH AND RISK OF VECTOR BORNE DISEASES
}

\author{
Nor Faiza M.T, Noor Artika Hassan, Mohammad Farhan R, Edre M.A, R.M Rus \\ Department of Community Medicine, Kulliyyah of Medicine, International Islamic University Malaysia. \\ *Corresponding Author Email: faizatohit@iium.edu.my
}

This is an open access article distributed under the Creative Commons Attribution License, which permits unrestricted use, distribution, and reproduction in any medium, provided the original work is properly cited.

\section{ARTICLE DETAILS}

\section{Article History:}

Received 19 October 2019 Accepted 23 November 2019 Available online 30 December 2019

\section{ABSTRACT}

Solid waste management is a growing challenge to many countries. The implications of poorly managed waste on health are numerous. Improper waste management serve as the breeding places for many vectors resulting in proliferation of vector-borne diseases. This article highlights the impact of improper solid waste management on the public health and the increase risk of vector-borne diseases.

\section{KEYWORDS}

Solid waste, health, vector-borne disease.

\section{INTRODUCTION}

Waste can be defined as the material that no longer has any value to the person who is responsible for it. It is generated by domestic, commercial, industrial, healthcare, agricultural and mineral extraction activities and accumulates in streets and public places. The words 'garbage,' 'trash,' 'refuses' and 'rubbish' are used to refer to some forms of waste [1]. The definition of 'solid waste' would be anticipated to be 'a waste in a solid state'. However solid waste may be solid, or liquid as a sludge or as a free chemical phase. Solid waste is mostly in a solid state, but also sludge from wastewater treatment and liquid chemical waste are included [2]. Inadequate solid waste management practices are a threat to public health and environment. Uncontrolled dumping and other undesirable practices pollute air through smells and smoke. Pollution of water resources and degradation of land will also take place. It will also foster the proliferation of disease-carrying vectors such as flies, mosquitoes and rodents that are directly or indirectly may have an adverse effect on public health.

Among the disease-transmitting insects, the mosquito is the greatest menace, spreading malaria, dengue and yellow fever, which together are responsible for several million deaths and hundreds of millions of cases every year. Mosquitoes also transmit lymphatic filariasis and Japanese encephalitis. Emergence and resurgence of these mosquito-borne diseases in tropical and subtropical regions are devastating. It is estimated that 500 million - one in every ten persons suffer from one or more tropical diseases and the global situation of lymphatic filariasis is reported as the fourth rank [3]. The geo-climatic conditions in South-East Asia are conducive for the transmission of vector-borne diseases. The magnitude of the mosquito menace and prevalence of mosquito-borne diseases depend upon various factors such as developmental activities, human interference, climatic changes, availability of parasitic load in the community and socio-cultural practices [4]. This article highlights the impact of improper solid waste management on the public health and the increase risk of vector-borne diseases.

\section{OVERVIEW OF SOLID WASTE}

The term "solid waste" means any garbage, refuse, or sludge from a waste treatment plant, water supply treatment plant, or air pollution control facility and other discarded material, including solid, liquid, semisolid, or contained gaseous material resulting from industrial, commercial, mining, and agricultural operations [2]. Depending on their source, solid waste can be classified into different types. Household waste is generally classified as municipal waste; industrial waste as hazardous waste, and biomedical waste or hospital waste as infectious waste. Solid waste is characterized based on following parameters: The sources, the types of wastes produced and by generation rates and composition. Based on guideline by EPA, solid wastes are characterized by these distinct features [2]:

- Corrosive: these are wastes that include acids or bases that are capable of corroding mental containers, e.g. tanks.

- Ignitability: this is waste that can create fires under certain condition, e.g. waste oils and solvents.

- Reactive: these are unstable in nature, they cause explosions, toxic fumes when heated.

- Toxicity: waste which are harmful or fatal when ingested or absorb.

Increase in the production of solid waste is caused mainly through urbanization and through industrial waste. Owing to population growth, poor levels of hygiene, and increasing urban poverty, the urban environment in many developing countries is rapidly deteriorating. The rapid rural-urban migration and population growth has resulted in overcrowded urbanization and increased densities of vectors such as mosquitoes, rats, and other pests. Consequently, it causes an increase in disease such as malaria, dengue and dengue haemorrhagic fever. In many developed and developing countries, the governmental services struggle to keep up with housing and sanitation needs. Modernization, technological advancement and increase in global population created rising in demand for food and other essentials. This has resulted to rise in the amount of waste being generated daily by each household.

Reducing the amount of solid waste that needs to be landfilled is the current solid waste management strategy. The direction is also focussing on recovering and utilizing the materials present in the discarded wastes. Different methods are used for treatment of solid waste and the choice of 
proper method depends upon refuse characteristics, land area available and disposal cost. The methods include incineration, compaction, pyrolysis, gasification and composting [5]. The most common methods of disposal are through landfilling or incineration. A modern, hygienic sanitary landfill will have a depression in an impermeable soil layer that is lined with an impermeable membrane. Heavy machinery will be used to spread out and compact the waste materials. Every day, a compacted soil will be used to cover the waste. Incineration is the process of burning municipal solid waste in a properly designed furnace under suitable temperature and operating conditions. It reduces the municipal solid waste by about $90 \%$ and $75 \%$ by weight [6]. Organic waste is disposed through a method of composting which uses the biodegradation technique. Bacterial decomposition of organic components of the municipal waste result in the formation of humus. It helps in disposal of solid waste, disposal of night soil, and production of valuable manure for crops, which is used as the fertilizers.

\section{IMPACTS OF SOLID WASTE ON HUMAN HEALTH}

There are several points by which solid waste may encounter contact with living organism. Mechanical transmission through insects, birds, rats, flies and animals may take place. They act as a vector that carries pathogenic microorganisms on their body and transfers them to food, which is then consumed by human beings. Direct dumping of untreated waste in seas, rivers and lakes results in the plants and animals that feed on it can also contribute to the contamination of our food and water resources. Waste landfill sites create potential hazard of ground water pollution. Pollutants that occur in leachate infiltrate to the soil, where they are carried to in underground water [7].

Soil adsorption, storage and biodegrading are the processes that influence dissolved organic matter in the soil. In tropical regions, climate conditions favour fast decomposition of soil organic matter (SOM), releasing into the soil organic composts in solid, liquid, and gaseous forms with variable compositions. Dissolved organic matter (DOM), a complex mixture of thousands of organic compounds, is only a small fraction of the decomposition products; however, it is highly mobile and reactive to the soil [8]. The group at risk from the unhygienic disposal of solid waste include the population in areas where there is no proper waste disposal method, especially the waste workers and workers in facilities producing toxic, and infectious material [5]. Other high-risk groups include the population living close to a waste dump and those whose water supply has become contaminated, either due to waste dumping or leakage from landfill sites. Uncollected solid waste also increases risk of injury and infection.

In several community health surveys, a wide range of health problems, including respiratory symptoms, irritation of the skin, nose, and eyes, gastrointestinal problems, psychological disorders, and allergies, have been discovered. The health effects include an increased risk of cancer and mortality, respiratory disease, congenital malformation and low birthweight; also, wellbeing is affected, through annoyance due to odour. The UNEPA (2006) states that wastes that are not properly managed, especially excreta and other liquids and solid wastes from households and the community, are a serious health hazard and could lead to the spreading of diseases [9]. The report further states that unattended wastes lying around attract flies, rats, and other creatures that, in turn, spread diseases. Normally, it is the wet waste that decomposes and releases bad odour. The bad odour affects the people settled next to the dumpsite, which clearly shows that the dumpsites have serious effects to people settled around or next to them [5].

Wastes from agriculture and industries can also cause serious health risks. Other than this, co-disposal of industrial hazardous wastes with municipal wastes can expose people to chemical and radioactive hazards. Uncollected solid waste can also obstruct storm water runoff, resulting in the forming of stagnant water bodies that become the breeding ground of disease [10]. Wastes dumped near a water source also cause a contamination of the water body or the ground water source. Direct dumping of untreated wastes in rivers, seas, and lakes, result in the accumulation of toxic substances in the food chain through the plants and animals that feed on it [11]. This clearly shows how waste disposal seriously affects the health of residents located closer to dumpsites. Industrial waste may include disposal of hazardous chemicals. Several health effects of primary concern may affect populations exposed to these hazardous chemicals. As reported by Vrijheid (2000), these health effects include [12]:

\section{- Carcinogenesis (i.e. causing cancers).}

- Genetic defects, including mutagenesis (i.e. causing alterations in genes which are transmitted from one generation to another or causing heritable genetic damage).

- Reproductive abnormalities including teratogenesis (i.e. causing damage to developing fetus not necessarily related to toxic effects on mother).

- Alterations of immunobiological homeostasis.

- Central nervous system (CNS disorder), and

- Congenital anomalies.

Invariably, exposure to chemicals escaping into the environment can lead to a reduction of life expectancy and possibly a period of reduced quality of life due to anxiety from exposures, diseases and stress. An uncontrolled waste disposal practice can therefore be perceived as a potential source of several health and environmental problems [13].

\section{RISK OF VECTOR BORNE DISEASES RELATED TO POOR SOLID WASTE MANAGEMENT}

The global burden of disease has been significantly contributed by vectorborne diseases and caused epidemics that disrupt health security and cause wider socioeconomic impacts around the world. The WHO estimates that one-sixth of the illness and disability suffered worldwide is owing to vector-borne diseases, with more than half of the world's population currently at risk [14]. Every year, more than one billion people are infected, and more than one million people die from vector-borne diseases, including malaria, dengue, schistosomiasis, leishmaniasis, Chagas disease and African trypanosomiasis [15]. The vector-borne diseases causing the greatest impact on humans is malaria, with an estimated 438, 000 related deaths worldwide in 2015 [16].

By the year 2050, the world is rapidly becoming urban and the global population living in cities is projected to be doubled. Urban environments create highly heterogeneous socio-economic and environmental conditions. Rapid, and often unplanned, urban growth is the source for many of the environmental hazards faced by cities within the developing world. Rapid growth of urban centres is always associated with substandard housing on marginal land, crowding, increasing levels of air pollution, water pollution and over usage, inadequate sanitation services, inadequate solid waste collection, and motor vehicle traffic and traffic injuries. The escalation in urbanization poses new challenges for the spread and control of vector-borne diseases. In urban and industrial areas, unused tyres, boxes, unused metal materials, plastic containers and discarded earthenware are the solid pollutants frequently observed to be dumped. As a result, they can create not only soil pollution but also act as potential health hazards. It can affect the transmission of vector-borne diseases dependent on human water storage and waste-water management. These solid wastes acting as containers that accumulate rainwater and may act as potential breeding sites. The resurgence of malaria, chikungunya and other mosquito borne diseases such as Japanese encephalitis and dengue has created concern in view of consequent morbidity and mortality to large number of human populations.

Most of the developing world face major problem in solid waste collection. Inadequate waste collection services present a variety of hazards, especially in the slums that often erected rapidly in any available space in and around the city. In addition, available landfill space is becoming harder to find as housing space for planned and squatter settlements competes with landfill space. To the abject poor, the small to large waste piles of the better off provide opportunities for recycling but place those sifting through trash at risk for injury from sharps, poisons, and animal bites. 
Incineration, as an alternative to landfill use, involves a large sum of tradeoffs. While reducing the demand for precious urban space, incineration of solid waste can increase air pollution and create new pollutants such as dioxin [17]. Uncollected solid waste may also prevent adequate water drainage and contribute to water pollution $[12,13,17]$.

A large and growing proportion of the population in many Southeast Asian cities live in slums and squatter settlement. This populations suffer from excessive exposure to insect and rodent vectors which transmit disease from one host to another. In such settlements, the quality of life, which is poor anyway, is made even worse by the high incidence of vector-borne diseases. Vector proliferation in high-density, low-income urban settlements is the consequence of several factors, such as lack of adequate housing, water supply, sanitation, drainage, and solid waste management facilities. One of the most common problems associated with the poorly designed and poorly managed landfills and solid waste is that it leads to attraction of large number of vectors of infectious disease, such as houseflies and mosquitoes. Tires, cans, or other items facilitating small collections of relatively clean water can serve as breeding places for mosquitoes such as Aedes sp. and Anopheles sp. $[6,12,13,17]$.

Solid waste clogs drain, creating stagnant water for insects breeding and floods during rainy season. Floods can robustly influence the incidence of vector- and water-borne diseases. The expansion in the number and range of vector habitats may indirectly lead to an increase in vector-borne diseases during floods. Standing water, that is stagnant pool of water caused by heavy rainfall or overflow of rivers can act as breeding sites for mosquitoes. It can harbour potential vector-borne diseases such as dengue, malaria and West Nile fever among the disaster-affected population and emergency workers. Initially, flooding may flush out mosquito breeding. However, as the water recedes, the mosquitoes may return and breed in the containers holding stagnant water. The lag time is usually around 6-8 weeks before the onset of a malaria epidemic and 34 weeks before the occurrence of dengue cases. The risk of outbreaks is greatly increased by changes in human behaviour such as increased exposure to mosquitoes while sleeping outside, a temporary pause in disease control activities and overcrowding. In addition, changes in the habitat which promote mosquito breeding such as landslide, deforestation, river damming, and rerouting may also increase the risk of outbreaks by many folds. Malaria epidemics as the impacts of vector populations was recorded in 1997-1998, when a substantial El Niño climate event caused significant flooding over eastern Africa. Large numbers of malaria deaths were subsequently reported in the northeastern lowlands of Kenya and in southwestern Uganda [18, 19].

\section{CONTROL OF ADVERSE IMPACT OF SOLID WASTE ON HEALTH AND VECTORS PROPAGATION}

It is critically important to address all the possible solutions to solid waste disposal problems. Proper solid waste management must be undertaken to ensure that it does not affect the environment and not cause health hazards to the public. In order to minimize their adverse effects on the human environment and to protect the health of the community, various stakeholders must carry out their specific roles. Solid waste management has been an integral part of every human society. In keeping with global trends, the systems are being oriented to concentrate on sustainability issues; mainly through the incorporation of 3R (reduce, reuse and recycle) technologies. Education of producers, the public and people who work in the waste sector should be increased. During the production of goods, the producers should opt for the use of less hazardous alternatives to hazardous chemicals. Materials that are suitable for recycling and recovery should be increased. Generation of waste should be decreased by promoting the production of goods which minimize waste generation after use.

The authority should play the major role in ensuring the success of solid waste management. Legislation in the waste sector should be improved, and more importantly, be enforced accordingly. Collection of hazardous waste at collection points shall be safe, secure and performed in an environmentally sound manner. Waste management through community mobilization must be empowered through awareness programmes. At the household-level proper segregation of waste must be done. Municipalities should increase their level of awareness and service to the public regarding sorting of waste. The process of separating solid waste at source involves separating solid waste according to waste composition such as recyclable waste, residual waste and bulky or garden waste. It should be ensured that all organic matter is kept aside for composting, which is undoubtedly the best method for the correct disposal of this segment of the waste. A large percentage of trash we accumulate, such as food waste and landscape and pruning waste is organic and biodegrades quickly. When these types of trash are composted, they can be reused as organic fertilizer, reducing the dependency on chemical fertilizers, which is known to have numerous side effects to the crops, soil and underground water resources.

In the context of vector control, "solid waste" refers mainly to nonbiodegradable items of household, community and industrial waste. An integrated and effective solid waste management can be used as a control strategy for propagation of vectors that involve in vector-borne diseases. Reduction of breeding places at household level could be an effective and sustainable dengue vector control strategy in areas where vector breeding takes place in small discarded water containers. Reduction, reuse and recycle approaches is highly applicable to bring down the number of discarded water containers. Proper disposal of solid waste into the dedicated bins and landfills can prevent clogging of water drainage system. It can also prevent the provision of food to the vectors such as rodents and flies. Tightly sealed plastic sacks should be used to collect the solid waste. Disposal of solid waste should be done as frequent as twice per week in warm climates country as a method for rodents and housefly control. Integration of vector control with waste management services is possible and should be encouraged.

\section{CONCLUSION}

Waste production, management and disposal involve a variety of complex activities. They have a great potential to affect health directly and indirectly, through many pathways and mechanisms. Subsequently, they will contribute to the increasing risk of vector-borne diseases following availability of suitable breeding places from the improperly managed waste. Integrated solid waste management by various stakeholders are crucial to prevent potential health hazards and propagation of vectorborne diseases.

\section{CONFLICT OF INTEREST}

None.

\section{AUTHORS' CONTRIBUTIONS}

Conception and design: NF, NA

Drafting of the article: NF, MFR, EA

Critical revision of the article for important intellectual content: NF, NA Final approval of the article: NF, NA, RMR, EA, MFR

\section{REFERENCES}

[1] Puri, A., Kumar, M., Johal, E. 2008. Solid-waste management in Jalandhar city and its impact on community health. Indian journal of occupational and Environmental medicine, 12 (2), 76.

[2] EPA. 2019. Criteria for the Definition of Solid Waste and Solid and Hazardous Waste Exclusions, EPA 2017https://www.epa.gov/hw/criteria-definition-solid-waste-and-solidand-hazardous-waste-exclusions Accessed on 18 December.

[3] WHO. 2019. World health report, Insect-borne diseases, WHO 1996 https://www.who.int/whr/1996/media_centre/executive_summary1/e n/index9.html_Accessed on 18 December.

[4] Vidyavathy, K. 2018. A study on solid waste management and vector borne diseases (Dengue) control in polluted areas (Warangal City).

[5] Alam, P., Ahmade, K. 2013. Impact of solid waste on health and the environment. International Journal of Sustainable Development and Green Economics (IJSDGE), 2 (1), 165-168. 
[6] Abdel-Shafy, H.I., Mansour, M.S. 2018. Solid waste issue: Sources, composition, disposal, recycling, and valorization. Egyptian journal of petroleum, 27 (4), 1275-1290.

[7] Szymański, K., Janowska, B., Iżewska, A., Sidełko, R., Siebielska, I. 2018. Method of evaluating the impact of landfill leachate on groundwater quality. Environmental monitoring and assessment, 190 (7), 415.

[8] Gmach, M.R., Cherubin, M.R., Kaiser, K., Cerri, C.E.P. 2019. Processes that influence dissolved organic matter in the soil: a review. Scientia Agricola, 77(3).

[9] United Nations Environment Program Agency (UNEPA). 2019. Informal Solid Waste Management," http://www.unep.org.PDF/Kenyawastemngntsector/chapter1.pdf_ Accessed on 20 December.

[10] Scragg, A.H. 2005. Environmental biotechnology. New York: OXFORD university press, 283.

[11] Medina, M. 2009. Municipal solid waste management in third world cities: lessons learned and a proposal for improvement. Human Settlement Development-Volume III, 264.

[12] Vrijheid, M. 2000. Health effects of residence near hazardous waste landfill sites: a review of epidemiologic literature. Environmental health perspectives, 108 (1), 101-112.

[13] Misra, V., Pandey, S.D. 2005. Hazardous waste, impact on health and environment for development of better waste management strategies in future in India. Environment international, 31 (3), 417-431.

[14] World Health Organization. 2008. The global burden of disease: 2004 update.

https://www.who.int/healthinfo/global_burden_disease/2004_report_u pdate/en/ Accessed on 19 December.

[15] Lozano, R., Naghavi, M., Foreman, K., Lim, S., Shibuya, K., Aboyans, V., AlMazroa, M.A. 2012. Global and regional mortality from 235 causes of death for 20 age groups in 1990 and 2010: a systematic analysis for the Global Burden of Disease Study 2010. The lancet, 380 (9859), 2095-2128.

[16] World Health Organization. 2019. World malaria report 2015. http://www.who.int/malaria/publications/world-malaria-report2015/report/en/. Accessed on 15 December.

[17] Ferronato, N., Torretta, V. 2019. Waste mismanagement in developing countries: A review of global issues. International journal of environmental research and public health, 16 (6), 1060.

[18] Brown, V., Issak, M.A., Rossi, M., Barboza, P., Paugam, A. 1998. Epidemic of malaria in north-eastern Kenya. The Lancet, 352 (9137), 1356-1357.

[19] Kilian, A.H.D., Langi, P., Talisuna, A., Kabagambe, G. 1999. Rainfall pattern, El Niño and malaria in Uganda. Transactions of the Royal Society of Tropical Medicine and Hygiene, 93 (1), 22-23. 